www.jmscr.igmpublication.org

Impact Factor 5.244

Index Copernicus Value: 83.27

ISSN (e)-2347-176x ISSN (p) 2455-0450

crossref DOI: _https://dx.doi.org/10.18535/jmscr/v4i10.118

Journal Of Medical Science And Clinical Research

IGM Publication

An Official Publication of IGM Publication

\title{
Study of Emergency Intestinal Resection and Anastomosis in Adults
}

\author{
Authors \\ Dr Aarti Mitra ${ }^{1}$, Dr Unmed Chandak ${ }^{2}$, Dr Ninad Sawant ${ }^{3}$, Dr Rachit Mitra ${ }^{4}$ \\ ${ }^{1,2}$ Associate Professor Department of Surgery, Government Medical College, Nagpur India \\ ${ }^{3}$ Resident, Department of Surgery, Government Medical College, Nagpur India \\ ${ }^{4}$ Intern, Indira Gandhi Medical College Nagpur India \\ Corresponding Author \\ Dr Ninad Sawant \\ Resident, Department of Surgery, Government Medical College, Nagpur India
}

\begin{abstract}
Aims and Objectives: (1) To study the emergency intestinal resection and anastomosis. (2) To study various intestinal pathologies for which emergency intestinal resection and anastomosis was performed. (3)To study various complications associated with emergency intestinal resection and anastomosis (4) To study the morbidity and mortality associated with emergency intestinal resection and anastomosis (5) To study various risk factors responsible for failure of emergency intestinal resection and anastomosis

Study Design: It was prospective study done over a period of 2 years conducted at a tertiary care hospital. All patients admitted to any surgical unit in our institute aged between 18-80 years in whom emergency intestinal resection and anastomosis was performed were enrolled in this study.

Materials and Methods: The study was approved by the Institutional ethical committee. The patients admitted in any surgical unit and fulfilling the criteria were enrolled in the study. After detailed history and detailed investigations the etiopathology, risk factors, complications, morbidity and mortaility patterns were studied in the patients who have undergone emergency resection and anastomosis. Failure of anastomosis along with risk factors were also studied.

Results: Amongst the studied cases $62(67.4 \%)$ were females and $30(32.6 \%)$ were males with an overall mean age of Mean age of 41.34 years. The minimum duration of complaints was 2 days while maximum duration of complaints was 15 days with a mean duration being 4.27 days. Most of the patients were anaemic and only one patient had Hb of more than $12 \mathrm{gm} \% .22$ (23.91\%) patients had Sr albumin levels less than $3.5 \mathrm{gm} \%$. Most common co-morbid conditions seen in patients was diabetes and hypertension which was seen in 7 (7.6\%) patients. 72 patients had no comorbidities. $44(47.82 \%)$ patient had evidence of some contamination either in the form of infected free fluid, pus , focal matter or combination of above. 19 (20.65\%) patients required some kind of inotropic support either before, during or after surgery. Out of the studied cases 48 (52.17\%) patients required blood or blood product transfusion. The most common pathologies for which emergency resection and anastomosis was done were stricture in small bowel and malignancy in large bowel. Most common anastomosis done was ileo-ileal which was done in 42 patients. Ileodescending and jejuno-ascending were done least frequently ie in 1 patient each. Drainage of peritoneal cavity was done in 78 (84.78\%) patients. The most common complications seen in the patients were wound infection and fever which were seen in $58(63.04 \%)$ and 42 (45.65\%) patients respectively. The mean duration of hospital stay was found to be 12.70 days and death occurred in 11(11.92\%) patients.

Conclusion: This study summarizes the main pathologies, risk factors, complications, morbidity and mortality rates and outcome in patients who have undergone emergency resection and anastomosis at a tertiary care hospital. In order to reduce complications it is important to know these risk factors and complication so that strategies to prevent, treat or reduce these complications can be made.

Keywords: Emergency resection and anastomosis, risk factors, complications.
\end{abstract}




\section{INTRODUCTION}

Gastrointestinal anastomosis is one of the most common procedure performed on the gastrointestinal tract. Despite advances in the techniques of surgeries anastomotic leaks and dehiscence still remain frequent and significant problems associated with such surgeries. They are responsible for increased morbidity and mortality in patients undergoing such surgeries. In elective uncomplicated surgeries healing of the intestinal tract is relatively rapid and postoperative complications are low because of adequate bowel preparation and preoperative antibiotics. But in many $5-15 \%$ instances patients have complications of obstruction, perforation, hemorrhage, acute inflammation, vascular compromise and haemodynamic instability doesnt allow for bowel preparation and emergency surgical interventions are requires ${ }^{[1]}$. These cases are associated with increased morbidity and mortaility. The complications which may be seen in these patients include surgical site infections, anastomotic leakage, post-operative bleeding, sepsis and ileus are some of the common complications ${ }^{[2]}$. Because of the large spectrum of indications for and the different extents of large or small bowel resections the spectrum and incidence of peri-operative complications differ. Another problem faced was lack of consensus as to how to define and grade post-operative complications. In 2004 Clavien and Dindo tried to classify the complications on the basis of therapy needed to treat these complications ${ }^{[3]}$. In general the complications of emergency resection and anastomosis can be decided into intra-operative and post-operative complications. Occurrence of intra-operative complications such as hemmorhage, bowel injury, ureteral or bladder injuries are caused by intra-abdominal adhesions, anatomic problems, the experience of the operating surgeons and any associated co-morbid conditions like thrombocytopenia, sepsis or presence of systemic illnesses like diabetes mellitus or hypertension ${ }^{[4]}$. Major postoperative complications include wound infection, anastomotic leakage, ileus and bleeding ${ }^{[5]}$. The risk factors for complications associated with emergency resection and anastomosis can be decided into preoperative, peri-operative and postoperative factors. Preoperative risk factors may be nonmodifiable (age, gender, prior surgeries, presence of systemic illnesses like diabetes mellitus or hypertension ) or modifiable (obesity, nutritional status, preoperative preparation, experience of operating surgeon, preoperative haemoglobin levels etc). Identifying modifiable risk factors enables targeting specific areas to improve thereby reducing post-operative complications is important. While this is sometimes possible in elective surgeries in cases of emergency resection and anastomosis even modifiable risk factors become non-modifiable due to lack of window period for surgical interventions ${ }^{[6]}$. The aim of our study was to study various intestinal pathologies, complications, morbidity and mortality associated with emergency anastomosis and resection and risk factors responsible for failure of emergency intestinal resection and anastomosis.

\section{MATERIALS AND METHODS}

All study patients were enrolled at a tertiary care hospital in a major city of India. This tertiary care centre serves as a major referral centre for Vidarbha region of Maharashtra. The study was done over a period of 2 years. It was a prospective, study conducted on patients belonging to all surgery units in whom emergency intestinal resection and anastomosis was done. The approval of ethical committee was obtained prior to conducting the study. A preoperative evaluation was done in all the patients. A complete history and clinical examination was done. Chest and abdomen radiography, urine sugar, albumin and ketones were done in all patients. ECG was done in patients above 40 years of age and when ever indicated. Random blood sugar, Blood urea, serum creatinineand electrolytes were done preoperatively in all patients. HIV and HBsAGwas also done before 
operation. After surgery a post operative evaluation was done in the form of complete blood count, Kidney function tests, random blood sugar, serum electrolytes and liver function test including serum albumin. Prolonged ileus, tachycardia, fever and evidence of bowel contents in the peritoneal drain and wound was considered as anastomotic failure and accordingly decision for re-exploration was taken. Ryles tube decompression was done in all patients in postoperative period. Passage of flatus or motion and presence of bowel sounds on auscultation was considered as return of bowel functions and accordingly oral feeding was started in a stepwise manner starting with liquids and gradually shifting to semisolids and solids. All emergency intestinal resection and anastomosis were done by open method. The anattomosis done was hand sewn, double layer, inverting end to end using vicryl 3-0 iepolyglactin 910-a co-polymer of lactide and glycolide for inner continuous layer and silk 3-0 half circle round bodied atraumatic needle for outer interrupted layer.

The adequacy of blood supply to anastomotic site was confirmed by presence of bleeding from the cut bowel ends, the colour of the bowel and the pulsations of the adjacent mesenteric vessels. On table bowel decompression was done in all patients except for the patients who were explored through inguinal incision for strangulated hernia. The anastomosis done was without any tension with absence of any distal obstruction. A rigorous toilet lavage of peritoneal cavity was done in all patients except for patients who were explored through inguinal incision. Pre and post operative antibiotics were given to all the patients. Intestinal staplers were not used for intestinal resection anastomosis because of higher cost and difficulty in procuring them in emergency situations. The demographic data was analysed. Use of inotropic support and blood or blood products if any was also documented. The analysis of pathology for which emergency surgical intervention was done and type of anastomosis done was also noted. In the end complications before during and after operation was noted down and its effect on duration of hospital stay was also analysed.

Inclusion criteria : (1) All patients admitted to any surgical unit aged between 18-80 years in whom emergency intestinal anastomosis was performed were enrolled in this study.

Exclusion criteria : (1) Patients who refused consent to be part of this study. (2) Patients with traumatic intestinal injury. (3) Referred patients who were earlier operated at some other hospital and needed emergency re-exploration and emergency intestinal resection anastomosis. (4) Patients with intestinal resection and proximal diversion were not included in this study.

\section{OBSERVATIONS AND RESULTS}

92 patients aged between 18 years to 80 years meeting the defined criteria for study in whom emergency intestinal anastomosis was performed were enrolled in this study. Mean age of the patients was 41.34 years (Graph 1).

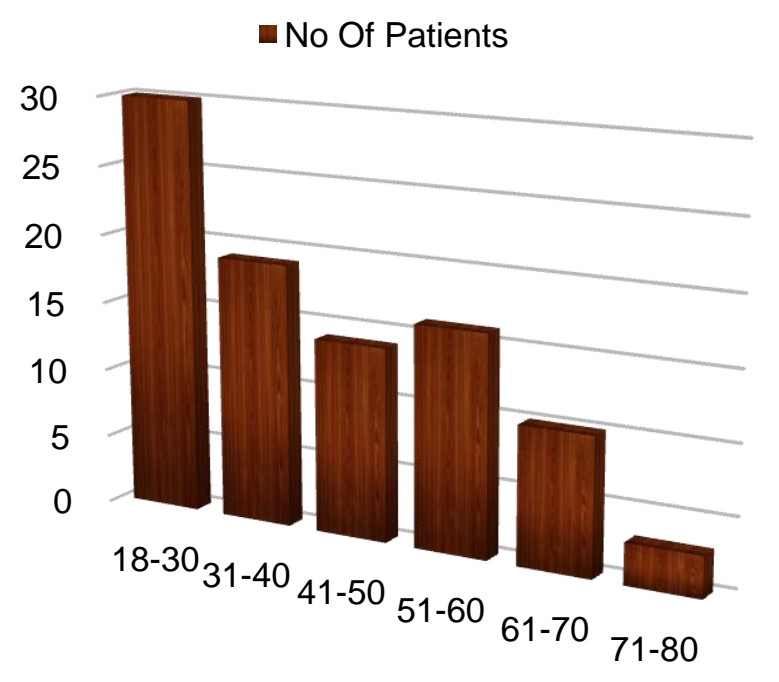

Graph 1 : Age Distribution of the studied cases. Majority of the patients were in the age group of 18-30 years (30), followed by 31-40 years (19), 51-60 years (16), 41-50 years (14). Least patients were found in age group of 61-70 (10) and 71-80 (3). The mean age of small bowel resection anastomosis was 40.87 years and for large bowel was 41.65 years. The youngest age for resection was 18 years and oldest patient was that of 75 years of age. 


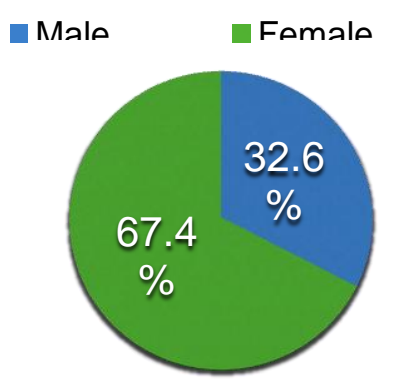

Graph 2 : Gender Distribution of studied cases Amongst the studied cases $62(67.4 \%)$ patients were female and 30 (32.6\%) were males (Graph 2).

The Mean Duration of complaints was 4.27 days. The minimum duration of complaints was 2 days and maximum duration of complaints was 15 days. The mean durationn of complaints for small bowel pathology was 4.15 days and for large bowel this duration was 4.58 days (Table 1 ).

Table 1: Duration of complaints in studied cases.

\begin{tabular}{|ccc|}
\hline Sr No & Days & No Of Patients \\
\hline 1 & 1 & 0 \\
2 & 2 & 19 \\
3 & 3 & 24 \\
4 & 4 & 12 \\
5 & 5 & 18 \\
6 & 6 & 3 \\
7 & 7 & 12 \\
8 & 8 & 1 \\
9 & 9 & 0 \\
10 & 10 & 2 \\
11 & 15 & 1 \\
\hline
\end{tabular}

Mean haemoglobin percentage observed in our study was $9.85 \mathrm{gm} \%$. Maximum number of patients were having haemoglobin in the range of 9.1- $10 \mathrm{gm} \%$. There was only one patient having haemoglobin> $12.0 \mathrm{gm} \%$. Post-Operative complication rate was found to be higher in patients with haemoglobin< $10 \mathrm{gm} \%$ (Table 2).
Table 2 : Haemoglobin percent distribution in patients.

\begin{tabular}{|c|c|c|}
\hline \multirow{2}{*}{ Sr No } & Hbgm \% & $\begin{array}{c}\text { No Of } \\
\text { Patients }\end{array}$ \\
\hline 1 & $7.1-8.0$ & 3 \\
\hline 2 & $8.1-9.0$ & 12 \\
\hline 3 & $9.1-10.0$ & 35 \\
\hline 4 & $10.1-11.0$ & 27 \\
\hline 5 & $11.1-12.0$ & 14 \\
\hline 6 & $>12$ & 1 \\
\hline & Total No Of Patients & 92 \\
\hline
\end{tabular}

Mean serum albumin in this study was $3.1 \mathrm{gm} \%$. Maximum number of patients in this study were having serum albumin more than 3.5 gm \%.Postoperative complications were morefrequently seen in patients with hypoprotinemia (Table 3 ).

Table 3 : Serum Albumin in Studied cases.

\begin{tabular}{|c|c|c|}
\hline Sr No & Serum Albumin & No of Patients \\
\hline 1 & $<3.5 \mathrm{gm} \%$ & 22 \\
\hline 2 & $>3.5 \mathrm{gm} \%$ & 70 \\
\hline & Total No Of Patients & 92 \\
\hline
\end{tabular}

The analysis of co-morbid conditions present in the patients revealed that 20 patients had one or the other co-morbid conditions. 1 patient had HIV infection (diagnosed pre-operatively). Two cases were of sickle cell disease out of which one was diagnosed pre-operatively.

Diabetes and hypertension were the most common co-morbid conditions. Post-operative complications rate was higher in patients with sickle cell disease (Table 4). 
Table 4 : Co-Morbid condition in patients.

\begin{tabular}{|c|c|c|}
\hline Sr No & Co-morbid conditions & No of Patients \\
\hline 1 & Pulmonary Kochs & 3 \\
\hline 2 & Hypertension & 4 \\
\hline 3 & Diabetes and Hypertension & 7 \\
\hline 4 & COPD & 3 \\
\hline 5 & Sickle cell disease & 2 \\
\hline 6 & HIV & 1 \\
\hline \multirow[t]{2}{*}{7} & No Co-Morbid conditions & 72 \\
\hline & Total No Of Patients & 92 \\
\hline
\end{tabular}

In our study out of 92 patients undergone emergency intestinal resection and anastomosis, $66(71.73 \%)$ cases were of small bowel and 26 (28.3\%) patients were of large bowels. The mortality rate was higher in the patients undergoing large bowel resection anastomosis which was $19.23 \%$ as compared to $9.09 \%$ in small bowel (Graph 3).

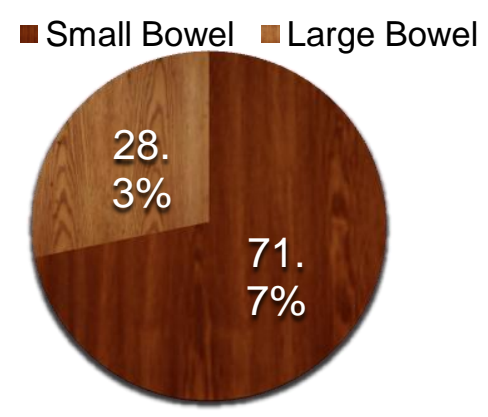

Graph 3: Small bowel and Large bowel involvement in studied cases

In the present series contamination of peritoneal cavity was present in 44 patients out of which 16 patients were having gross peritoneal contamination. Post-operative complication rate was higher in patients having pus or focal matter in the peritoneal cavity (Table 5).
Table 5 : Contamination of peritoneal cavity.

\begin{tabular}{|c|c|c|}
\hline Sr no & Type of Contamination & $\begin{array}{c}\text { No of } \\
\text { Patients }\end{array}$ \\
\hline 1 & Infected free fluid & 28 \\
\hline 2 & Infected free fluid + Pus & 6 \\
\hline 3 & Infected free fluid+ Fecal matter & 4 \\
\hline 4 & Infected free fluid + Pus+Fecal & 6 \\
\hline 5 & No Contter & 48 \\
\hline & Total no of patients & 92 \\
\hline
\end{tabular}

Majority of the patients didn't require any inotropic support. Hypotension before, during and after operation is known to affect the healing of intestinal anastomosis. In this study the anastomotic failure rate and mortality rate was higher in the patients requiring inotropic support as compared to patients with no inotropic support (Table 6)

Table 6 : Inotropic support in patients .

\begin{tabular}{|c|c|c|}
\hline Sr No & Inotropic support & $\begin{array}{c}\text { No of } \\
\text { Patients }\end{array}$ \\
\hline 1 & Pre-Operative & 0 \\
\hline 2 & Intra-operative & 1 \\
\hline 3 & Intra and post operative & 15 \\
\hline 4 & post-operative & 2 \\
\hline 5 & Throughout & 1 \\
\hline 6 & No Support & 73 \\
\hline & & 92 \\
\hline
\end{tabular}

Blood transfusions are known to cause immunosuppression. In our study out of 92 patients 48 patients required blood or blood component transfusion either intra or postoperatively.

Blood transfusion was not found to be risk factor for anastomotic leak as it was indicated in most of the patients and found to be useful in this study (Table 7). 
Table 7 : Blood and blood product transfusion in patients.

\begin{tabular}{|c|c|c|}
\hline Sr No & Blood / Blood Products & No of patients \\
\hline 1 & Whole Blood & 43 \\
\hline 2 & Whole Blood+ FFP & 3 \\
\hline 3 & Whole Blood+ FFP+ Platelets & 2 \\
\hline 4 & No Transfusion & 44 \\
\hline & Total No of Patients & 92 \\
\hline
\end{tabular}

The analysis of pathologies requiring emergency intestinal anastomosis revealed that most common pathology requiringg surgical intervention was carcinoma colon with obstruction which was seen in 10 patients followed by small bowel volvulus with strangulation which was seen in 8 patients. Least common causes were abdominal lochs with obstruction, jejunal diverticulum with perforation and mockers diverticulitis amongst others. In this is study the most common pathology for which emergency intestinal resection anastomosis was carried out was stricture for small bowel and malignancy for large bowel (Table 8).

Table 8 : Pathology in Patients

\begin{tabular}{|c|c|c|}
\hline Sr No & Type of Pathology & $\begin{array}{l}\text { No of } \\
\text { Patients }\end{array}$ \\
\hline 1 & $\begin{array}{l}\text { Tubercular jejunal stricture with } \\
\text { obstruction }\end{array}$ & 1 \\
\hline 2 & $\begin{array}{l}\text { Jejunal diverticulum with } \\
\text { perforation }\end{array}$ & 1 \\
\hline 3 & $\begin{array}{l}\text { Jejunal perforation of unknown } \\
\text { cause }\end{array}$ & 3 \\
\hline 4 & $\begin{array}{l}\text { Tubercular ileal stricture with } \\
\text { obstruction }\end{array}$ & 5 \\
\hline 5 & $\begin{array}{l}\text { Tubercular ileal stricture with } \\
\text { obstruction with perforation }\end{array}$ & 4 \\
\hline 6 & ileal perforation of unknown cause & 1 \\
\hline 7 & $\begin{array}{c}\text { Jejunal/ Ileal stricture of unknown } \\
\text { cause }\end{array}$ & 6 \\
\hline 8 & Enteric ileal perforation & 7 \\
\hline 9 & Meckels diverticulitis & 1 \\
\hline 10 & Meckels diverticulitis with & 2 \\
\hline
\end{tabular}

\begin{tabular}{|c|c|c|}
\hline Sr No & Type of Pathology & $\begin{array}{c}\text { No of } \\
\text { Patients }\end{array}$ \\
\hline & perforation & \\
\hline 11 & $\begin{array}{l}\text { Meckels diverticulum causing } \\
\text { obstruction due to adhesions }\end{array}$ & 2 \\
\hline 12 & $\begin{array}{l}\text { Small bowel obstruction due to } \\
\text { bands with strangulation }\end{array}$ & 1 \\
\hline 13 & $\begin{array}{c}\text { Post- Op adhesive intestinal } \\
\text { obstruction with gangrene \& } \\
\text { Perforation }\end{array}$ & 1 \\
\hline 14 & $\begin{array}{l}\text { Post-Op Adhesive intestinal } \\
\text { obstruction }\end{array}$ & 6 \\
\hline 15 & $\begin{array}{l}\text { Small bowel volvulus with } \\
\text { strangulation }\end{array}$ & 8 \\
\hline 16 & $\begin{array}{c}\text { Small bowel gangrenee of unknown } \\
\text { cause }\end{array}$ & 2 \\
\hline 17 & $\begin{array}{l}\text { Mesentric vascular thrombosis with } \\
\text { small bowel gangrene }\end{array}$ & 6 \\
\hline 18 & Strangulated Inguinal hernia & 4 \\
\hline 19 & Strangulated femoral hernia & 3 \\
\hline 20 & $\begin{array}{c}\text { Carcinoma small bowel with } \\
\text { obstruction }\end{array}$ & 1 \\
\hline 21 & Intussusception & 3 \\
\hline 22 & $\begin{array}{l}\text { Sigmoid volvulus with } \\
\text { a) Obstruction } \\
\text { b) Strangulation } \\
\text { c) Perforation }\end{array}$ & $\begin{array}{l}6 \\
2 \\
1\end{array}$ \\
\hline 23 & $\begin{array}{l}\text { Carcinoma colon with } \\
\text { a) Obstruction } \\
\text { b) Strangulation with perforation }\end{array}$ & $\begin{array}{c}10 \\
2\end{array}$ \\
\hline 24 & Caecal volvulus with strangulation & 1 \\
\hline \multirow[t]{2}{*}{25} & $\begin{array}{c}\text { Inflammatory bowel disease with } \\
\text { perforation }\end{array}$ & 2 \\
\hline & Total No Of Patients & 92 \\
\hline
\end{tabular}

The most common intestinal anastomosis done was ileo-ileal $(45.65 \%)$ ) for small bowel and descending rectal $(7.61 \%)$ for large bowel (Table 9). 
Table 9 : Site of Anastomosis in Patients.

\begin{tabular}{|c|c|c|}
\hline Sr no & Site of Anastomosis & $\begin{array}{c}\text { No of } \\
\text { patients }\end{array}$ \\
\hline 1 & Jejuno-jejunal & 6 \\
\hline 2 & Jejuno-ileal & 8 \\
\hline 3 & Ileo-ileal & 42 \\
\hline 4 & Ileo-ascending & 12 \\
\hline 5 & Jejuno-ascending & 1 \\
\hline 6 & Ileo-transverse & 7 \\
\hline 7 & Ileo-descending & 4 \\
\hline 8 & Transverse-sigmoid & 4 \\
\hline 9 & Descending-sigmoid & 92 \\
\hline 10 & Descending-Rectal & 7 \\
\hline & Total Number of Patients & 1 \\
\hline
\end{tabular}

There has been a great deal of disagreement regarding the ability of abdominal drainage to protect an anastomosis. In this Study out of 92 patients, peritoneal drain was kept in 78 patients. Most of the patients were having peritoneal contamination. Drains were usually helpful for the detection of anastomotic leak apart from other parameters of anastomotic leak (Table 10).

Table 10 : Drainage of peritoneal cavity.

\begin{tabular}{|c|c|c|}
\hline Sr No & Drainage & No of Patients \\
\hline 1 & Done & 78 \\
\hline 2 & Not Done & 14 \\
\cline { 2 - 3 } & Total No Of Patients & 92 \\
\hline
\end{tabular}

In this study the most common post-operative complication was wound infection (63.84\%) followed by fever $(45.65 \%)$ and pulmonary complications $(36.96 \%)$.

The anastomotic failure rate was $19.57 \%$ and mortality was $11.96 \%$. The feral fistula developed in $7.16 \%$ of patients. In this the Study 13 patients developed anastomotic failure for which 11 patients required re-exploration. The mean hospital stay was also prolonged after reexploration thus increasing the morbidity (Table $11)$.
Table 11: Post Operative complications in studied subjects.

\begin{tabular}{|c|c|c|}
\hline Sr No & Complications & No of Patients \\
\hline 1 & Nausea & 1 \\
\hline 2 & Vomitings & 0 \\
\hline 3 & Prolonged Ileus & 9 \\
\hline 4 & Electrolyte Imbalance & 7 \\
\hline 5 & Wound Infection & 58 \\
\hline 6 & Wound Dehiscence & 20 \\
\hline 7 & Burst Abdomen & 6 \\
\hline 8 & Fever & 42 \\
\hline 9 & Intra-Abdominal Collection & 11 \\
\hline 10 & Clinical Anastomotic Leak & 12 \\
\hline 11 & Radiological Anastomotic Leak & 1 \\
\hline 12 & Anastomotic Dehiscence & 5 \\
\hline 13 & Fecal Fistula & 7 \\
\hline 14 & Anastomotic Stricture & 0 \\
\hline 15 & Pulmonary Complications. & 34 \\
\hline 16 & Death & 11 \\
\hline
\end{tabular}

The utility of any surgical procedure is judged by the post-operative hospital stay. Emergency intestinal resection is not an exception to this rule. The combined (small and large bowel resection anastomosis) mean hospital stay was 12.70 days (Table 12).

Table 12 : Hospital stay in patients.

\begin{tabular}{|c|c|c|}
\hline Sr.No & Days in hospital & No of Patients \\
\hline 1 & 7 to 10 & 46 (2 deaths) \\
\hline 2 & 11 to 15 & 21 (1 death) \\
\cline { 2 - 3 } 3 & 16 to 20 & 6 \\
\hline 4 & 21 to 25 & 3 \\
\hline 5 & 26 to 30 & 5 \\
\hline 7 & 31 to 35 & 1 \\
\hline 8 & 36 to 40 & 0 \\
\hline 9 & 41 to 45 & 0 \\
\hline 10 & 46 To 50 & 0 \\
\hline
\end{tabular}




\begin{tabular}{|c|c|c|}
\hline Sr.No & Days in hospital & No of Patients \\
\hline 11 & 56 to 60 & 0 \\
\hline 12 & 61 to 65 & 1 (1 death) \\
\hline 13 & Deaths in < 4 days & 7 \\
\hline & Total No Of Patients & 92 \\
\hline
\end{tabular}

In this study death occurred in 11 patients. Anastomosis failure rate and mortality was higher in patients who required inotropic support, patients with hypoprotinemia and patients having gross peritoneaal contamination on exploration. When these 3 factors were present, increased age and anaemia contributed to the anastomotic failure and mortality.

\section{DISCUSSION}

Intestinal resection and anastomosis is performed for many diseases such as colorectal cancer, ulcerative colitis, abdominal lochs with strictures, Crohn's disease, mechanical bowel obstruction and recurrent diverticulitis, small bowel volvulus with strangulation, enteric fever complicated by perforation and postoperative strictures. This intestinal resection and anastomosis in many of the cases is done as elective surgeries. Elective surgical interventions give appropriate time to surgeon to treat co-morbid conditions like diabetes, hypertension, anaemia and sepsis etc before undertaking surgery. But in many of the cases these surgeries are to be done on emergency basis where there is no time to treat co-morbid conditions and also there is no time for bowel preparation. These patients are prone for developing peri-operative and post-operative complications more than what is seen in patients operated electively.

Very few studies have been done on risk factors, morbidities and complications associated with emergency intestinal resection. Moreover it is difficult to study such complications and risk factors because of the varied etiology for which such emergency surgeries are undertaken ${ }^{[7]}$.

One of the important factors to be considered while planning emergency resection and anastomosis is concerned is age of the patient . In elder patient these is higher incidence of presence of co-morbid conditions like diabetes, hypertension, coronary artery disease and anaemia ${ }^{[8]}$. young patient undergoing emergency surgeries are less likely to have co-morbidities and consequently have shorter length of hospital stay ${ }^{[9]}$. There are some studies which have concluded that male gender is associated with higher risk of complications and anastomotic leak after intestinal resection and anastomosis ${ }^{[10]}$.

Emergency small bowel resection and anastomosisis required in many pathologies like adhesions, strangulated hernia, chrons disease, strictures, tubercular perforations, carcinoma small bowel with obstruction and gangrene ${ }^{[11]}$. Whereas common causes of large bowel pathologies requiring emergency surgical interventions are diverticulitis, hernia, ileus, intussusception, volvulus, postoperative adhesions, colorectal malignancy, carcinoids and gastrointestinal stroll tumours ${ }^{[12]}$.

One of the important factors determining the outcome of patients who have undergone emergency resection and anastomosis is occurrence of peritonitis. Because in cases of emergency resection and anastomosis there is no time for adequate bowel preparationn there is always a possibility of focal contamination of peritoneal cavity. This contamination can occur peri-operatively or can take place due to anastomotic dehiscence after colonic or small bowel resection. This complication severely affects the patients health and may require further surgical interventions thereby increasingng duration of hospital stay and mortality ${ }^{[13]}$.

The need for using inotropes and blood components is usually dependent upon the individuall patient. While inotropes are usually not required during emergency resection and anastomosis it may be essential while dealing with the patient having significant hypotension before, during or after surgical procedure. Its of utmost importance that the harm-dynamic stability of the patient is maintained during peri-operative and post -operative period because significant 
hypoximeia and hypotension are known to cause delayed healing of anastomosis site thereby increasing the incidence of leaks and subsequent stricture formation ${ }^{[14]}$.

Use of blood and blood products like packed cell volume, fresh frozen plasma and platelets is necessary in many patients undergoing emergency surgical interventions. unlike in elective surgeries where treating surgeon usually gets time to correct anaemia by iron supplementation, in emergency surgical interventions the only emergency measure available for correction of anaemia is blood transfusion ${ }^{[15]}$. Other blood products like Packed cell volume, fresh frozen plasma and platelets are used in special circumstances. While in many cases blood and blood products transfusion is necessary and withholding such transfusion may risk the life of patient by predisposing the patient for hemorrhagic shock and hypotension, there are studies which have concluded that blood transfusion has an independent and significant association with poor prognosis in surgeries done in colorectal cancer patients ${ }^{[16]}$. Aquina et al in their study found that receipt of a blood transfusion was independently associated with an increased risk of postoperative infectious complications. In this study the authors emphasised the creation and implementation of perioperative blood transfusion protocols aimed at limiting unwarranted variation in between different hospital set ups ${ }^{[17]}$.

Various types of anastomosis are done in cases of gastrointestinal resection. The site of anastomosis depends upon many factors which include, type of pathology, site of pathology and length of segment involved. In our study most of the patient underwent ileo-ileal anastomosis. Many studies have found that complication rates like anastomotic leak and wound dehiscence were least in ileo-ileal anastomosis ${ }^{[18]}$. The complications were reported to be higher in cases of colocolic or colorectal anastomosis ${ }^{[19]}$. Multiple resection due to any cause was associated with increased Intraabdominal sepsis in many studies ${ }^{[20]}$.
In cases where surgical resection and anastomosis has been done drains are expected to prevent collection of fluid, hematoma formation or frank pus collection. These drains may also act as an indicator of postoperative complication, they also minimize symptoms once the complications has started occurring. There is a lot of controversy regarding whether or not a drainage should be used in all patients ${ }^{[21]}$ but still many surgeons routinely use these drains at least for warning function in case of anastomotic leakage ${ }^{[22]}$. There is a relatively recent concept of collection of biomarkers from the drain. These biomarkers include interleukins, TNF-alpha, glucose, lactate, glycerol and $\mathrm{pH}$. The levels of these biomarkers may indicate presence or absence of infection, acidosis, hypoximea and ischemia ${ }^{[23]}$.

Common complications after surgery involving resection and anastomosis include nausea, vomitings, electrolyte imbalance, post-operative ileus, infection, anatomic leakage, intraabdominal access, bleeding and consequent shock, focal fistula, strictures and pulmonary complications. While these complications are unavoidable in some instances there is need of standardization of postoperative care to minimize postoperative complications ${ }^{[24]}$. Reducing the incidence of these complications will reduce the hospital stay, financial burden on the patient and consequently reduce the morbidity and mortality in patients undergoing various surgeries ${ }^{[25]}$.

Conclusion: Due to varied pathological processes requiring emergency resection and anastomosis there are very few studies analysing the risk factors, complications, morbidity patterns and failure rates in cases where emergency resection and anastomosis is done This study summarizes the main pathologies, risk factors, complications, morbidity and mortality rates and outcome in patients who have undergone emergency resection and anastomosis at a tertiary care hospital. In order to reduce complications it is important to know these risk factors so that strategies to prevent, treat or reduce these complications can be made. 
Conflict of Interest: None

\section{REFERENCES}

1. Herrington JL, Lawler M, Thomas TV, Graves HA. Colon resection with primary anastomosis performed as an emergency and as a non-planned operation. Annals of Surgery. 1967;165(5):709-720.

2. Kirchhoff P, Clavien P-A, Hahnloser D. Complications in colorectal surgery: risk factors and preventive strategies. Patient Safety in Surgery. 2010;4:5.

3. Dindo D, Demartines N, Clavien P-A. Classification of Surgical Complications: A New Proposal With Evaluation in a Cohort of 6336 Patients and Results of a Survey. Annals of Surgery. 2004;240(2):205-213.

4. Artinyan A, Nunoo-Mensah JW, Balasubramaniam S, Gauderman J, Essani R, Gonzalez-Ruiz C, Kaiser AM, Beart RW Jr. Prolonged postoperative ileusdefinition, risk factors, and predictors after surgery. World J Surg. 2008;32:14951500 .

5. Shaffer VO, Baptiste CD, Liu Y, et al. Improving Quality of Surgical Care and Outcomes: Factors Impacting Surgical Site Infection after Colorectal Resection. The American surgeon. 2014;80(8):759-763.

6. Hyman N, Manchester TL, Osler T, Burns B, Cataldo PA. Anastomotic Leaks After Intestinal Anastomosis: It's Later Than You Think. Annals of Surgery. 2007;245(2):254-258.

7. Binda GA, Karas JR, Serventi A, Sokmen S, Amato A, Hydo L, Bergamaschi R; Study Group on Diverticulitis.. Primary anastomosis vsnonrestorative resection for perforated diverticulitis with peritonitis: a prematurely terminated randomized controlled trial. Colorectal Dis. 2012 Nov;14(11):1403-10.

8. Turrentine FE, Wang H, Simpson VB, Jones RS.Surgical risk factors, morbidity, and mortality in elderly patients. $\mathrm{J}$ Am Coll Surg. 2006 Dec;203(6):865-77.

9. Krell RW, Girotti ME, Dimick JB. Extended length of stay after surgery: complications, inefficient practice, or sick patients? JAMA Surg. 2014 Aug;149(8) :815-20.

10. Lipska MA, Bissett IP, Parry BR, Merrie AE. Anastomotic leakage after lower gastrointestinal anastomosis: men are at a higher risk. ANZ J Surg. 2006 Jul;76(7):579-85.

11. Vallicelli C, Coccolini F, Catena F, et al. Small bowel emergency surgery: literature's review. World Journal of Emergency Surgery : WJES. 2011;6:1.

12. Sawai RS. Management of Colonic Obstruction: A Review. Clinics in Colon and Rectal Surgery. 2012;25(4):200-203.

13. Ruggiero R, Sparavigna L, Docimo G, Gubitosi A, Agresti M, Procaccini E,Docimo L. Post-operative peritonitis due to anastomotic dehiscence after colonic resection. Multicentric experience, retrospective analysis of risk factors and review of the literature.AnnItalChir. 2011 Sep-Oct;82(5):369-75.

14. Chen K-N. Managing complications I: leaks, strictures, emptying, reflux, chylothorax. Journal of Thoracic Disease. 2014;6(Suppl 3):S355-S363.

15. Tartter PI. The association of perioperative blood transfusion with colorectal cancer recurrence. Annals of Surgery. 1992;216(6):633-638.

16. Edna TH, Bjerkeset T. Perioperative blood transfusions reduce long-term survival following surgery for colorectal cancer. Dis Colon Rectum. 1998 Apr;41(4):451-9.

17. Aquina CT, Blumberg N, Probst CP, Becerra AZ, Hensley BJ, Noyes K, Monson JR, Fleming FJ. Large Variation in Blood Transfusion Use After Colorectal Resection: A Call to Action. Dis Colon Rectum. 2016 May;59(5):411-8. 
18. Van Laarhoven CJHM, Andriesse GI, Schipper MEI, Akkermans LMA, van Vroonhoven TJMV, Gooszen HG. Ileoneorectal Anastomosis: Early Clinical Results of a Restorative Procedure for Ulcerative Colitis and Familial Adenomatous Polyposis Without Formation of an Ileoanal Pouch. Annals of Surgery. 1999;230(6):750.

19. Calin M, Bălălău C, Popa F, Voiculescu S, Scăunașu R. Colic anastomotic leakage risk factors. Journal of Medicine and Life. 2013;6(4):420-423.

20. Iesalnieks I, Kilger A, Glass H, MüllerWille R, Klebl F, Ott C, Strauch U, Piso P, Schlitt HJ, Agha A. Intraabdominal septic complications following bowel resection for Crohn's disease: detrimental influence on long-term outcome. Int $\mathrm{J}$ Colorectal Dis. 2008;23:1167-1174.

21. Tsujinaka S, Konishi F. Drain vs No Drain After Colorectal Surgery. Indian journal of surgical oncology. 2011;2(1):3-8.

22. Hoffmann J, Shokouh-Amiri MH, Damm P, Jensen R. A prospective, controlled study of prophylactic drainage after colonic anastomoses. Dis Colon Rectum. 1987;30(6):449-452.

23. Komen N, Bruin RW, Kleinrensink GJ, Jeekel J, Lange JF. Anastomotic leakage, the search for a reliable biomarker.A review of the literature. Colorectal Dis. 2008;10(2):109-115.

24. Clavien PA, Barkun J, de Oliveira ML, Vauthey JN, Dindo D, Schulick RD, de SE, Pekolj J, Slankamenac K, Bassi C, Graf R, Vonlanthen R, Padbury R, Cameron JL, Makuuchi M. The ClavienDindo classification of surgical complications: five-year experience. Ann Surg. 2009;250:187-196.

25. Rogers JP, Dobradin A, Kar PM, Alam SE. Overnight Hospital Stay After Colon
Surgery for Adenocarcinoma. JSLS : Journal of the Society of Laparoendoscopic Surgeons. 2012;16 (2):333-336. 